\title{
RACHEL DE QUEIROZ: UMA MULHER À FRENTE DO SEU TEMPO
}

\author{
Maria Eveuma de Oliveira \\ Manoel Freire \\ Sérgio Wellington Freire Chaves
}

RESUMO: A relação da mulher com a literatura e com o mundo da escrita tem sido objeto de estudo de vários historiadores. Os romances de Rachel de Queiroz se destacam por enfatizarem aspectos sociais e tratarem de valores de uma época nas várias tramas que vivem seus personagens. $\mathrm{O}$ artigo objetiva mostrar a relevância do trabalho da escritora como fomento da escrita feminina para a literatura brasileira.

PALAVRAS-CHAVE: História. Expressão literária. Gênero. Trabalho.

ABSTRACT: The woman's relationship with literature and with the world of writing has been studied by many historians. The novels of Rachel de Queiroz stand out by emphasizing the social aspects and treat the values of a time in the various plots that his characters live. The article aims to show the relevance of the work of the writer as encouraging women's writing for the Brazilian literature.

KEYWORDS: History. Literary expression. Genre. Labor.

\section{CONSIDERAÇÕES INICIAIS}

Minhas mulheres são danadas, não são? Talvez seja ressentimento do que não sou e gostaria de ser. Rachel de Queiroz

Um dos fenômenos mais evidentes, nestes últimos anos, no âmbito dos estudos universitários (sobretudo nas áreas das Ciências Sociais, da Literatura e da História) é o crescente interesse pelas pesquisas acerca do mundo feminino, tal como ele se revela no registro histórico e/ou literário do passado, ou como pode ser captado, fragmentariamente, na literatura feminina do presente. Tais pesquisas se multiplicam, empenhadas principalmente em revelar e compreender o que as mulheres de ontem pensavam e diziam a respeito delas próprias (muitas vezes contrariando a visão dominante na sociedade), bem como o que a sociedade pensava e/ou exigia delas.

O porquê desse interesse pelo mundo feminino é evidente. Já se sabe que, entre as grandes revoluções inovadoras que estão em processo em nosso tempo, a que abala os 
alicerces do antigo mundo feminino é das mais decisivas, pois atinge as próprias bases da sociedade como um todo. No rastro das grandes mutações político-econômico-sociais que se aceleraram no século $\mathrm{XX}$, as relações homem-mulher foram profundamente alteradas e, consequentemente, se alterou o sistema familiar: a mulher transpõe os limites do lar (onde há séculos cumprira o papel de "rainha do lar" que o sistema patriarcal lhe destinara) e ingressa no mercado de trabalho, assumindo as mais diversas funções, inclusive aquelas que antes eram de domínio exclusivo dos homens.

A mulher no Brasil era formada pela ordem patriarcal e submetida ao pai e ao marido, que a silenciavam em sua própria sociedade. Com esta submissão, a mulher era reduzida à condição de um ser frágil e de "pouca inteligência", destinando-se a ela apenas a função de "dona de casa", de modo que todo o conhecimento que adquiria era fruto de suas próprias experiências de vida, limitando-se, portanto, ao universo doméstico.

Segundo Coelho (2002), nos anos 1930, enquanto o movimento pela emancipação da mulher avançava na Europa e nos Estados Unidos, no Brasil eram fracas suas repercussões, mas "A literatura estava destinada a desempenhar um papel decisivo na denúncia daquele descompasso e daquela barreira" (COELHO, 2002, p. 246), e neste aspecto Rachel de Queiroz é reconhecidamente uma das pioneiras. Ela cumpre um papel valioso no processo de discussão da educação feminina no Brasil e, ao mesmo tempo, chama a atenção para o papel importante da literatura na educação, ressaltando seu potencial na formação do sujeito.

A expressão literária de Rachel de Queiroz realiza-se através de uma narrativa plenamente sintonizada com o espírito dos anos 1930, empenhado não só em compreender a realidade brasileira, mas também em denunciar as nossas mazelas sociais. Daí a valorização do regional, a linguagem precisa e objetiva, com marcas de oralidade, em que a terra e a tradição falam mais alto. Destacam-se, nas narrativas da autora cearense, além da mulher sertaneja como heroína, vários motivos regionalistas, tais como a seca, a política arcaica das oligarquias, o misticismo, o cangaço etc.

Nota-se, desde $O$ quinze, a preocupação da autora com as personagens femininas, e é Conceição a primeira de uma série que marcará esta espécie de projeto literário para configurar o papel da mulher nordestina. Daí porque Maria Alice Barroso escreve sobre a importância da atuação da escritora na história da literatura brasileira a partir da sua primeira obra: “É com Rachel de Queiroz na prosa da ficção, que a fala da mulher ingressou no campo 
social, abandonando os salões de chá para narrar a áspera tragédia da seca nordestina" (BARROSO, 2008, p. 46).

Partindo desses pressupostos o artigo objetiva mostrar a relevância do trabalho da escritora Rachel de Queiroz como contribuição da escrita feminina para o desenvolvimento da literatura brasileira.

\section{HISTÓRIA DE UM NOME: RACHEL DE QUEIROZ}

Na verdade, mais de um: Rita de Queluz, Conceição, Guta, Maria do Egito, Dôra, Maria Moura; na verdade, um: Rachel. Cadernos de Literatura brasileira, 2002, pág.09.

Não sem razão, Rachel de Queiroz é considerada uma das mais importantes escritoras brasileiras do século XX. Desde os seus primeiros escritos, publicados sob o pseudônimo de Rita de Queluz, acumulou inúmeras vitórias. Deixou sete romances, todos aclamados pela crítica, inúmeras traduções de autores clássicos, peças de teatro, livros infanto-juvenis e memorialistas. Teve sua obra adaptada para o cinema e para a televisão com grande sucesso (o que, até certo ponto, contribuiu para aumentar a popularidade), e foi ainda a primeira mulher a entrar para a Academia Brasileira de Letras.

Apesar do prestígio social e do reconhecimento literário que conquistara, quando the perguntavam sobre as suas atividades nas letras, Rachel não hesitava e respondia: "Antes de mais nada, sou uma jornalista". Essa era sua atividade regular, com a qual sobrevivia financeiramente e através da qual se situava, muitas vezes com grande coragem, no espaço público da sociedade brasileira.

Já aos dezesseis anos de idade, Rachel de Queiroz assumiu a direção da página literária do jornal $O$ Ceará, onde ganhava cem mil-réis por mês. Na mesma época, começou a escrever um esboço de um romance, um folhetim chamado A história de um nome, que segundo ela foi influenciado pelo clima de Os Maias, de Eça de Queirós, que acabara de ler. O folhetim, publicado em meados de 1927, foi escrito em sete capítulos. O impulso inicial da narrativa começa com a descrição da autora ao ver as letras do nome Rachel ganhar vida e movimento: 
(...) vi o $\mathrm{R}, \mathrm{o} \mathrm{A}, \mathrm{o} \mathrm{C}$ e as demais letras tomarem, respectivamente, as formas de cabeça, tronco e membros de um corpo que, cruzando as pernas e erguendo um braço, numa gesticulação affectada, assumia a pôse de uma conferencista em plena actividade... (RACHEL, apud ACIOLI, 2003, p.49).

A partir disso, a própria palavra Rachel vai contando a sua história, personificada na vida de muitas mulheres, começando com Rachel bíblica, filha de Labão (autora altera o texto bíblico à sua maneira). No segundo capítulo, apresenta narrações de histórias no Egito e em Israel, mas o nome lamenta a monotonia de sua função: "Não me proporcionavam as emoções que exigia o meu espírito de nome romanesco... uma vida de incrível monotonia: nascer, casar, procriar, morrer" (RACHEL, apud ACIOLI, 2003, p.50).

Do terceiro ao quinto capítulos, o nome Rachel é dado a várias mulheres na Idade Média: à filha de um ourives, a uma freira que morre de tuberculose, a uma filha de camponês que se aventura por outras terras, atravessando os mares. Depois, no sexto capítulo, o nome chega ao Brasil. O nome Rachel vai terminar sua narrativa na própria autora da história, Rachel de Queiroz. Segundo análise de Cecília Maria Cunha (2000), o folhetim A história de um nome é um pretexto literário para afirmar-se como a romancista que ela seria posteriormente, mestra em desenvolver representações femininas. Neste escrito inicial Rachel de Queiroz antecipou o assunto que seria a marca de sua produção literária: a mulher.

No quadro de sua atividade regular na imprensa, foi na crônica que concentrou a maior parte de sua colaboração. Foi a crônica o espaço onde melhor registrou suas lembranças, opiniões, afetos, bem como as suas indignações. O espaço da crônica no jornal era quase um diário que a acompanhou por 77 anos. Como afirmava Rachel com frequência, a imprensa era sua "trincheira", e foi ainda neste gênero (a crônica), que mal se define entre o jornalismo e a literatura, que a autora mais experimentou os limites de sua escrita.

\section{A DAMA SERTANEJA DAS LETRAS}

Rachel de Queiroz surge em 1930 com o romance $O$ quinze, quase três anos depois do aparecimento de A bagaceira (1928), de José Américo de Almeida (livro que ela não havia lido ainda, mas que muitos críticos apontam como obra influente na criação do romance da escritora cearense, dada a semelhança do tema). Escrito numa "prosa enxuta e viva que seria 
depois tão estimável na crônica de Rachel de Queiroz" (BOSI, 1994, p. 446), em O quinze a autora relata o problema da seca com crueza, obtendo o prêmio da fundação Graça Aranha. Estas palavras indicam o impacto causado pela obra:

Parecia espantoso que uma jovem de vinte anos tivesse tomado como tema de suas veleidades literárias - ao contrário do lirismo religioso de uma Auta de Sousa ou do lirismo pagão de uma Gilka Machado e mesmo tão longe da novelística burguesa de D. Júlia Lopes de Almeida - uma realidade tão trágica como o drama das secas. Foi enorme a repercussão de seu livro e seu nome se firmou definitivamente em nossos meios intelectuais, tanto pela sua obra de ficção, como pela sua atividade de cronista, isto é, de comentadora dos acontecimentos da vida real (TAMURU, 2006, p.42).

Rachel de Queiroz adveio de uma família de intelectuais, portanto não seria surpreendente o rigor que aplicou em seu ofício de escrita. Ela mesma relatou tal influência familiar: a mãe foi a primeira a colocar um livro em suas mãos, assim que, sozinha, aprendera a ler, soletrando os cabeçalhos dos jornais. Em sua casa, todo mundo lia: a mãe, o pai, as tias e o avô. Seguindo a orientação materna, não a puseram em escola primária, mas lhe forneceram livros para ela ler e contar depois o que havia lido. O pai iniciava-a na política, lendo trechos de discursos de Rui Barbosa, que ele adorava, mas que ela achava "maçantes". Porém, com ele aprendeu o que significava democracia, eleição, candidatura etc. Já a mãe não se interessava por política, mas por literatura, e fascinava-se com Tostoi, Dostoiévski, Gorki, Balzac, Anatole France, Eça de Queiroz etc; e, no Brasil, Machado de Assis. Deixou à filha cerca de cinco mil volumes e os ensinamentos necessários à carreira de escritora:

Quando comecei a escrever, era ela a minha crítica mais severa. Censurava as banalidades, os lugares comuns, os entusiasmos e o que ela chamava "as exclamações". [...] Nunca publiquei livro que não passasse por severa revisão dela (QUEIROZ, apud. TAMURU, 2006, p.43).

Na casa da família Queiroz, a leitura, mais do que um hábito, ocupava um lugar de destaque. Lia-se sempre e lia-se de tudo: livros, jornais, revistas. A infância de Rachel foi certamente povoada pela emoção e pelas fantasias geradas por essas leituras, que iriam repercutir em toda a sua obra. Rachel não escondia sua grande predileção pela ficção científica de Júlio Verne e por um livro específico: Vinte mil léguas submarinas. "Foi pelas mãos de Júlio Verne que, no silêncio do açude do Junco, Rachel passava horas e horas sonhando com aventuras em alto-mar" (HOLLANDA, 2005, p. 13). O primeiro romance 
brasileiro que leu foi A mão e a luva, de Machado de Assis, e a partir daí passou a devorar nossos autores com um entusiasmo raro de ser encontrado em leitores tão jovens.

Desse modo, a prática de leitura utilizada na formação de Rachel mostra que ela era condicionada a ler os autores e livros orientados pela mãe, conforme ela relata em entrevista: "Minha mãe foi formando meu gosto de pequena" (ARAÚJO, 1998). Apesar de gostar dos autores ingleses, lia mais os autores franceses e portugueses por indicação da mãe. É notório que a autora teve uma extrema influência das bibliografias indicadas pela mãe.

Portanto, é nesse quadro, em contato direto com o texto escrito, que representava "uma coisa normal" no ambiente doméstico de Rachel de Queiroz, que ela se apropriou de uma vasta literatura, "efeito de um processo cultural dinâmico, vindo de apropriações, de posturas diante do objeto-escrita, de usos e funções desse objeto em determinados espaços" (MOYSÉS, 1995, p. 58), o que veio refletir e manifestar-se em suas representações do meio social e cultural.

Por volta de 1915, uma grande seca atingiu o sertão nordestino, e consequentemente o Estado do Ceará, trazendo consequências dramáticas para toda a população dos sertões. A família Queiroz não fugiu à regra: perdeu toda sua extensa plantação de arroz e quase todo seu gado, com grande prejuízo econômico para a família (HOLLANDA, 2005, p. 13). A experiência e a memória desta seca marcaram de forma indelével a obra de Rachel de Queiroz, constituindo a matéria para a composição do seu romance de estreia, $O$ quinze.

Além dos aspectos propriamente literários, o primeiro romance da escritora cearense trazia algo que por si mesmo era uma novidade: era um "livro de autoria feminina", que se desenhava sobre a figura de uma mulher forte e independente, com evidentes traços sociais, livre pensamento e ação. Alguns sequer acreditavam que o livro pudesse ter sido escrito por uma mulher tão jovem, pois exprimia os anseios e angústias da população de uma vasta região, assunto considerado sério demais para ser tratado por uma moça de vinte anos de idade. Graciliano Ramos é um exemplo desse posicionamento, como comprova seu depoimento muito revelador sob esse aspecto:

O Quinze caiu de repente ali por meados de 30 e fez nos espíritos estragos maiores que o romance de José Américo, por ser livro de mulher e, o que realmente causava assombro, de mulher nova. Seria realmente mulher? Não acreditei. Lido o volume e visto o retrato no jornal, balancei a cabeça: Não há ninguém com este nome. É pilhéria. Uma garota assim fazer romance! Deve ser pseudônimo de sujeito barbado (RAMOS, apud Hollanda, 2004, p.9-10). 
Percebe-se daí como se figurava a situação da mulher intelectual na sociedade brasileira dos anos 1930. Pode-se igualmente perceber a força com que se apresentava a autora cearense, no campo da literatura, mostrando de forma ímpar e diferencial a construção de suas personagens femininas: mulheres livres e independentes, que respondiam aos conflitos políticos da década de 1930 e de um momento em que a literatura assumia a tarefa de "pesquisar" para melhor conhecer e compreender a realidade social do país (HOLLANDA, 2005). Alguns traços da própria pessoa de Raquel estavam compondo o desenho da sua primeira personagem feminina, a Conceição, de $O$ quinze. É no sertão, e tendo por cenário o sertão, que o romance é elaborado, região que define o espaço ocupado pela personagem, que tinha consciência do drama social vivido pelo homem nordestino. Começa, portanto, a viagem literária de Rachel: o trânsito entre a cidade e o sertão; a eterna fuga da seca e o descrédito do amor romanesco.

A trilogia O quinze (1931), João Miguel (1932) e Caminho de pedras (1937) marca visivelmente um momento da obra de Rachel. Mostra o compromisso da escritora com uma literatura "empenhada", para usar a expressão de Antonio Candido (1997), engajada na discussão dos problemas inerentes à realidade do país, daí sua opção por uma linguagem clara, de expressão moderna, literatura mais adequada para exprimir e denunciar aos problemas da sociedade brasileira, em conformidade, portanto, com o espírito modernista. Marca ainda a sua literatura uma capacidade particular para a criação de "personagens femininas cujo desempenho desafia invariavelmente a lógica patriarcal da primeira metade do século XX.” (HOLLANDA, 2005, p. 20).

No ano de 1939, Rachel de Queiroz escreve As três Marias, romance que apresenta alguns traços autobiográficos, ligados à sua vivência no Colégio Imaculada Conceição. Neste romance a autora surpreende com uma escrita em primeira pessoa, em que faz referências diretas às suas experiências no colégio, conforme nos diz Hollanda (2005). Passados 36 anos, a autora volta ao cenário da literatura brasileira com outro romance, Dôra, Doralina (1975), o qual apresenta diferenças marcantes em relação à sua obra anterior. "Temos agora um romance de fôlego, tecnicamente maduro, atingindo um invejável nível de excelência de linguagem e estrutura de ação" (HOLLANDA, 2005, p.25). Dôra agora começa a explicitar com maior intensidade a força dos perfis femininos das heroínas criadas pela autora cearense, que apresentam a mesma disposição do homem para se aventurar a um tipo de existência 
instável e errante, onde as experiências se renovam como forma de integração, de fuga ou de descoberta interior.

Dois anos após a publicação de Dôra, Doralina, Rachel de Queiroz era eleita para a Academia Brasileira de Letras (5 de agosto de 1977), sendo, portanto, a primeira mulher a ocupar uma cadeira naquela instituição. Aqui também Rachel reafirma o seu pioneirismo, dando "continuidade a uma carreira que se tornaria símbolo da afirmação das mulheres no cenário nacional" (HOLLANDA, 2005, p. 26), como também fora a primeira mulher aceita como representante do movimento modernista, de acordo ainda Heloísa Buarque de Hollanda.

O romance Memorial de Maria Moura (1992) encerra de forma exemplar o trabalho de Rachel de Queiroz como criadora de perfis femininos de mulheres fortes e independentes que conduzem suas próprias histórias. As mulheres criadas pela autora se condensam em Maria Moura, síntese das personagens femininas da escritora. A não continuidade familiar, a vida errante e a "desobediência" às normas da sociedade patriarcal são características inerentes às protagonistas de Raquel de Queiroz. No caso de Maria Moura é através do incesto que se opera o rompimento com os valores e regras de uma sociedade, deixando de ser objeto de troca e libertando-se, tornando-se indivíduo (HOLANDA, 2005, p. 28-9).

A galeria de personagens femininas de Rachel de Queiroz, segundo ainda Hollanda, (2005, p. 29), “instaura o direito da mulher de defesa de sua individualidade e autodeterminação". Podemos verificar na sua obra que o encontro amoroso, apesar de ser sempre muito intenso, resolve-se constantemente pela perda da pessoa amada. Outro aspecto curioso da obra de Rachel é a falta de descendência em todas as suas personagens femininas, de modo que a continuidade familiar expressa pela descendência não tem lugar em sua obra. Suas personagens femininas trilham caminhos individuais difíceis, e no mais das vezes acabam derrotadas por fazerem essa opção (HOLLANDA, 2005).

\section{MULHER DIFERENTE E INQUIETANTE: UMA MULHER QUE VIVEU PARA} ESCREVER

Até o início do século $\mathrm{XX}$ as escritoras estiveram praticamente ausentes dos registros das consideradas grandes historiografias brasileiras. Nos compêndios de história literária, foram, em sua maioria, colocadas à margem pelos agentes que construíram o cânone. Apesar 
dessa lógica, surgiu na década de 1930 uma desbravadora a forçar passagem, cujas marcas não puderam deixar de ser percebidas. Uma Maria Moura que pensou o Brasil de um novo modo, com uma visão muito independente, com o senso crítico de intelectual e a coragem de mulher sertaneja. Essa desbravadora é Rachel de Queiroz, como nos mostra Heloísa Buarque de Hollanda:

Foi a única escritora mulher aceita como representante do movimento modernista. Foi uma das primeiras mulheres a se propor, com sucesso, uma vida independente e livre. Foi uma mulher que escolheu e determinou seu destino afetivo, existencial, literário, profissional, político. Foi uma mulher que viveu de e para o ofício de escrever (HOLLANDA, 2004, p. 297).

As contribuições da autora cearense extrapolam o ambiente literário e a luta pelo reconhecimento da qualidade do trabalho feminino, e sua obra, nitidamente engajada na discussão de problemas cruciais da sociedade brasileira, pode ser considerada como um inventário das ideias que ela presenciou em quase um século da atividade intelectual.

Dedicou-se exclusivamente ao ofício de escrever, seja nas atividades de jornalista, seja como tradutora, ou como autora de obras literárias (cronista/romancista), Rachel adquiriu aquele "teto todo seu" explicitado por Virgínia Woolf (2004), demarcando não apenas seu espaço, mas novos caminhos para as obras de autoria feminina, de forma que toda escritora que surgiu no Brasil depois dos anos 1930 pode ser considerada herdeira de Raquel em algum aspecto.

De acordo com Virgínia Woolf, a falta de condições materiais que garantissem um mínimo de bem estar e privacidade teria ocasionado a marginalização das escritoras no campo literário. Ao longo de suas reflexões, Virgínia identificou possíveis obstáculos, afirmando que a maior de todas as liberações seria a liberdade de pensar nas coisas em si, de classificar, selecionar, emitir opinião (WOOLF, 2004).

Se os homens escritores encontravam dificuldades para construir o seu projeto literário, para as mulheres essas dificuldades eram bem maiores, pois havia não apenas indiferença, mas também hostilidade. Para serem reconhecidas, as mulheres escritoras deveriam alterar os seus valores em deferência à autoridade externa, reproduzindo as normas ditadas pelo discurso masculino. De igual modo, outro obstáculo a ser superado, depois de conquistado o direito à escrita, era a ausência de uma tradição, ou uma tradição curta e parcial que pouco favorecia. As próprias formas literárias foram criadas pelos homens a partir de suas 
necessidades e para as suas aplicações. Todos os gêneros mais antigos de literatura já estavam consolidados à época em que as mulheres se tornaram escritoras, e apenas o romance era suficientemente novo para ser maleável a elas, afirma Woolf (2004).

É bem verdade que Rachel de Queiroz tornou-se figura polêmica não tanto pelo conjunto de sua obra literária, que embora sofra alguma restrição num ou noutro aspecto, é suficientemente reconhecida pela crítica, mas principalmente pelas posições políticas contraditórias que assumiu ao longo de sua vida. Como a maior parte dos escritores de esquerda, Rachel militou no Partido Comunista no início da década de 1930, porém demonstrou simpatia pelo golpe militar de 1964, o que a fez sofrer um processo de “sombreamento" (para utilizar o termo de Heloísa Buarque de Hollanda), e atrair a rejeição de parte da crítica acadêmica de esquerda.

Tristão de Athayde (apud TAMARU, 2006) conta-nos sobre o caráter marcante da individualidade de mulher e de escritora que, talvez, fosse um dos segredos do enorme e merecido prestígio intelectual de Rachel de Queiroz. Sem perder o contato com a vida de cada dia e ligada aos grandes problemas políticos e sociais do país, a autora cearense deu uma valiosa contribuição para a compreensão da realidade brasileira, tanto com seus romances quanto com as crônicas semanais que escreveu durante sua carreira de escritora, sempre reavivando os valores de sua terra natal.

Durante o curto período que vai de 1931 a 1933, Rachel de Queiroz ligara-se ao Partido Comunista do qual fora expulsa como trotskista, convicta de que o stalinismo traíra o leninismo e a revolução transformara-se em simples fascismo soviético. Assim é narrado em seu livro de memórias, escrito a duas mãos com sua irmã Maria Luiza de Queiroz:

Quando nele entrei, o Partido mal completara dez anos de vida no Brasil. E já havia uma rede de comunistas pelo país inteiro: onde a gente chegava, encontrava amigos. [...] Era mister dar provas durante anos, principalmente no que se referia à submissão ideológica ao stalinismo. Pois essa foi a fase mais temível do stalinismo, logo depois da morte de Lenin. Quando me tornei trotskista, Trotski já fora, havia três anos, expulso da Rússia. E o PC brasileiro de então já estava bem organizado. Talvez a rede não fosse imensa, mas era estendida, ocupava todo o país. E uma vez que no sistema de 1930, tempo de ilegalidade, ninguém podia ir abertamente se manifestar na rua, aproveitavam-se, então, os movimentos liberais, como por exemplo, a revolução de São Paulo em 1932. A primeira vez em que o comunismo mostrou a cara na rua foi em 1935; mas, antes disso, descoberto qualquer movimento ilegal, a repressão era implacável. Talvez por isso mesmo nós víssemos na revolução um certo colorido romântico, o apelo, a fascinação do proibido. Na verdade, éramos os revolucionários mais ingênuos do mundo (QUEIROZ, apud. TAMURU, 2006, p.45-46). 
A emancipação profissional não impediu a escritora de constituir família, tendo sido casada por duas vezes, a primeira com Zé Auto, com quem teve uma filha, Clotilde, que faleceu por volta dos dois anos de idade, de meningite, perda da qual nunca se recuperou. Sua vida intelectual e seu envolvimento partidário eram partilhados com o marido, com quem viveu um período em Itabuna-BA, seguindo depois para São Paulo, nos conturbados anos da Revolução de 1932. Posteriormente, Raquel voltou a Fortaleza, onde se lançou a um novo projeto:

Foi então que um dia resolvi tomar decisão radical. Eu estava enjoada da minha vida, enjoada de tudo. O casamento não ia bem. Resolvi trabalhar no comércio. Procurei emprego na firma G. Gradhvol et Fils, uma firma de judeus, onde me encarreguei da correspondência em francês e inglês (QUEIROZ, apud. TAMURU, 2006, p.62).

Rachel de Queiroz sempre foi uma mulher diferente e inquietante. Seu único objetivo fora ser feliz. Conseguiu se realizar tanto no lado profissional como afetivo. Foi uma mulher que escolheu e determinou seu destino afetivo, existencial, literário, profissional e político.

\section{CONSIDERAÇÕES FINAIS}

Portanto, podemos seguramente afirmar que Rachel de Queiroz foi e continua sendo um grande nome da literatura brasileira, e sua obra um importante marco na escrita literária entre nós, haja vista seu pioneirismo como escrita de autoria feminina e expressão da visão de mundo feminina numa sociedade dominada pelos valores patriarcais. Foi uma mulher que viveu de e para o ofício de escrever, o que era raro para o seu tempo, e continua sendo nos dias de hoje.

De qualquer modo, seja representando a mulher como ser oprimido, atado às amarras da ideologia patriarcal, que subjuga o sexo feminino, seja criando figuras engajadas no processo de transformação social, que reivindicam o direito de preservação da identidade, seja ainda representando mulheres liberais, capazes de decidir o rumo que desejam imprimir à própria história, o fato é que a tradição da literatura de autoria feminina está consolidada no Brasil, e sem dúvidas a escritora cearense contribuiu decisivamente para essa consolidação. 
Rachel de Queiroz é autora de uma literatura cujo foco se encontra na terra e nas mulheres de sua região, nos embates com que se deparam, por isso considerada autora "regionalista". Porém, o fato de ter como cenário o interior nordestino não impede que a sua obra tenha um alcance nacional, na medida em que revela e denuncia as mazelas de uma sociedade conservadora e injusta, regida pelos valores arcaicos da estrutura patriarcal, que não se restringiam ao sertão nordestino. A literatura da autora se constrói, assim, pelas brechas possíveis entre a luta da nova mulher (nordestina, mas não só) que busca se impor, e a ideologia patriarcal que tenta encerrar a mulher no espaço da casa e dos afazeres domésticos, cíclicos como a ameaça da seca que paira sobre seus corpos.

\section{REFERÊNCIAS:}

ACIOLI, Socorro. Rachel de Queiroz. Fortaleza: Edições Demócrito Rocha, 2003.

ARAÚJO, Felipe. Os Anos da Razão. O Povo. Fortaleza, da Editoria do Sábado - 26.09.1998. Disponível em: <http://www.revista.agulha.nom.br/1faraujo02c.html.> Acesso em 12 out 2011.

BARROSO, Maria Alice. A mulher na literatura brasileira. In Seminário de Literatura Brasileira - ensaios. Rio de Janeiro: UFRJ, 2008.

BOSI, Alfredo. História concisa da literatura brasileira. 3 ed. São Paulo: Cultrix, 1994.

BOURDIEU, Pierre. A dominação masculina. 4. Ed. Rio de Janeiro: Bertrand Brasil, 2005.

CANDIDO, Antonio. Formação da literatura brasileira. 8 ed. Belo Horizonte: Rio de Janeiro: Itatiaia, 1997. v. 2.

COELHO, Nelly Novaes. Dicionário Crítico de Escritoras Brasileiras. São Paulo: Escrituras Editora, 2002.

CUNHA, Cecília Maria. Vida literária em formação. In: jornal O Povo (Fortaleza - CE), 17 de novembro de 2000.

HOLLANDA, Heloísa Buarque de. Rachel de Queiroz. Rio de Janeiro: Agir, 2005.

HOLLANDA, Heloísa Buarque de. In: HOLLANDA, Heloísa Buarque de (Compiladora). Melhores crônicas: Rachel de Queiroz. São Paulo: Global, 2004.

MOYSÉS, Sarita Marisa Affonso. Literatura e História: Imagens de leitura e de leitores no Brasil no século XIX. In: Revista Brasileira de Educação. UNICAMP: nº 0. p. 53-62, set/out/dez, 1995. 
NERY, Hermes Rodrigues. Presença de Rachel. Rio de Janeiro: FUNPEC, 2002.

QUEIROZ, Rachel de. Obra completa. Vols 1-5. Rio de Janeiro: Ed. José Olympio, 1989.

QUINTELLA, A. et al. Cadernos da Literatura Brasileira, Instituto Moreira Salles, número 4, setembro de 1997, $1^{\text {a }}$ reimpressão - janeiro de 2002.

TAMURU, Angela. A construção literária da mulher nordestina em Rachel de Queiroz. São Paulo: Scortecci, 2006.

WOOLF, Virgínia. Um teto todo seu. 2. Ed. Rio de Janeiro: Nova Fronteira, 2004.

XAVIER, Elódia. Tudo no feminino: a presença da mulher na narrativa brasileira contemporânea. Rio de Janeiro: Francisco Alves, 1991.

RECEBIDO EM: 07 de maio de 2012

APROVADO EM: 12 de junho de 2012 